\title{
Índice de satisfação da necessidade de água do feijão-caupi sob sistema de cultivo convencional e plantio direto
}

\author{
Aderson Soares de Andrade Junior ${ }^{1(*)}$, Edson Alves Bastos ${ }^{1}$, Marcos Vinicius Pereira da Silva ${ }^{2}$, Josimar Soares da Silva Junior ${ }^{2}$ e \\ José Eduardo Boffino de Almeida Monteiro ${ }^{3}$ \\ ${ }^{1}$ Embrapa Meio-Norte. Av. Duque de Caxias, nº 5.650, Bairro Buenos Aires, Caixa Postal 001 CEP 64008-780, Teresina, PI. \\ E-mails: aderson.andrade@embrapa.br e edson.bastos@embrapa.br \\ ${ }^{2}$ UFPI-Programa de Pós-graduação em Agricultura Tropical. Campus Universitário Ministro Petrônio Portela, Bairro Ininga, CEP 64049-550 Teresina, PI. \\ Teresina, PI. E-mails: marquim06vinicios@gmail.com e josimarssjunior@gmail.com \\ ${ }^{3}$ Embrapa Informática Agropecuária, Rua André Tosello, 209, Barão Geraldo, Caixa Postal 6041, CEP 13083-886 Campinas, SP. \\ E-mail: eduardo.monteiro@embrapa.br \\ ${ }^{(*)}$ Autor para correspondência.
}

\section{INFORMAÇÕES}

História do artigo:

Recebido em 23 de junho de 2018

Aceito em 2 de dezembro de 2018

Termos para indexação:

balanço hídrico

extração de água

ISNA

risco climático

\section{RESUMO}

O objetivo deste estudo foi estimar e comparar o índice de satisfação da necessidade de água (ISNA) do feijão-caupi quando cultivado sob sistema plantio direto em relação ao cultivado sob preparo convencional do solo, visando subsidiar o zoneamento agrícola de risco climático (ZARC) do feijão-caupi em sistema plantio direto. Utilizou-se modelo de balanço hídrico no solo para estimativa da evapotranspiração real (ETr) e ISNA do feijão-caupi, em diferentes condições de disponibilidade de água no solo. Foram utilizados coeficientes de cultivo (Kc) quantificados em ensaios de campo conduzidos em ambos sistemas de cultivo. Em cenário sem deficiência hídrica no solo, não houve variação nos valores de ISNA nas fases de desenvolvimento do feijão-caupi. Porém, em condição de deficiência hídrica nas fases II, III e IV, os valores de ISNA em cultivo sob palhada foram superiores 18,6\% (fase II), 32,1\% (fase III) e 15,8\% (fase IV) em relação ao sistema de preparo convencional, devido ao acréscimo na disponibilidade de água no solo com a adoção da palhada. Essa condição favorece a ampliação da janela de plantio considerada de baixo risco climático para a cultura.

\section{Introdução}

O feijão-caupi [Vigna unguiculata (L.) Walp] é cultura de importância socioeconômica para as regiões Nordeste e Norte do Brasil, devido ao seu baixo custo de produção e por ser importante fonte de proteína para as populações de baixa renda dessas regiões (Freire Filho, 2011). Contudo, como é cultivado especialmente sob regime de sequeiro, a produtividade de grãos é altamente dependente do regime pluviométrico das regiões de cultivo. A irregularidade do período chuvoso associada a outros fatores como solos arenosos, temperaturas elevadas e manejo inadequado, são os principais fatores responsáveis pelo baixo rendimento de grãos da cultura (Cardoso et al., 2017). 
Em um cenário climático dessa natureza, o zoneamento agrícola de risco climático (ZARC) assume grande importância por identificar áreas com condições edafoclimáticas satisfatórias ao desenvolvimento das culturas, possibilitando melhor aproveitamento das suas potencialidades genéticas, apresentando ganhos de produtividade aliado às reduções de perdas (Oliveira, 2010). É instrumento importante para a política agrícola do país, já que as indicações do ZARC são utilizadas como base para financiamento do custeio da atividade agrícola, bem como a contratação de seguro agrícola pelos bancos oficias e seguradoras privadas (Cunha e Assad, 2001).

O zoneamento agrícola de risco climático permite, a partir do conhecimento das variabilidades climáticas locais (como por exemplos a precipitação e a evapotranspiração de referência) e de sua espacialização regional por meio de um sistema de informação geográfica (SIG), definir regiões de aptidão climática e épocas mais adequadas de semeadura como forma de diminuir os efeitos causados pela má distribuição de chuvas (Andrade Júnior et al., 2007).

O sistema de plantio direto pode ser considerado vantajoso em relação ao sistema de plantio convencional para a cultura do feijão-caupi, por utilizar resíduos de cultura para cobertura do solo com a finalidade de manter a umidade, diminuindo o risco da cultura ao déficit hídrico (Simidu et al., 2010), tornando-se prática de cultivo indicada para a redução do risco climático para a cultura na condição sob plantio direto (Meireles et al., 2003).

A presença de palhada na superfície do solo, em quantidade adequada, altera a relação solo-água, reduzindo a taxa de evaporação de água do solo (Dalmago e Bergamaschi, 2017) e elevando a disponibilidade de água para as plantas, principalmente nos estádios em que o dossel destas não cobre totalmente o solo (Stone et al., 2006), reduzindo assim o risco de frustação de safra por deficiência hídrica no solo (Meireles et al., 2003).

A relação entre a evapotranspiração real (ETr) e a evapotranspiração máxima da cultura (ETm) determina o índice de satisfação da necessidade de água da cultura (ISNA), ou índice de penalização, que varia de zero a um, e representa a fração entre a quantidade de água consumida pela planta em determinada condição hídrica no solo e a quantidade que seria demandada para se garantir a máxima produtividade, sem ocorrer restrição hídrica no solo
(Assad et al., 1998).

Valores distintos de ISNA têm sido usados para quantificar o risco climático do feijão-caupi em diferentes condições ambientais (Andrade Junior et al., 2001; Meireles et al., 2003; Amaral et al., 2005). Porém, a quantificação do risco tem sido efetuada com base em valores de ISNA definidos para sistemas de cultivo que preconizam o preparo convencional do solo, o que já não é mais uma realidade nas regiões produtoras de grãos. O feijão-caupi vem se constituindo uma alternativa de cultura de safrinha, cultivada sob palhada, especialmente, em sucessão ao milho e a soja.

O objetivo deste estudo foi estimar e comparar o ISNA do feijão-caupi quando cultivado sob sistema plantio direto em relação ao cultivado sob preparo convencional do solo, admitindo-se diferentes cenários de disponibilidade de água no solo, visando subsidiar o ZARC da cultura sob plantio direto.

\section{Material e Métodos}

O estudo foi realizado para as condições de clima e solo do muncípio de Teresina, Piauí ( $5^{\circ} 05$ 'S, 42²9'W e 74,40 m). o clima da região, segundo a classificação climática de Thornthwaite e Mather, é C1sA'a (subúmido seco). Considerando os registros históricos de 1980 a 2014, apresenta as seguintes médias anuais: temperatura média de $28,1^{\circ} \mathrm{C}$, umidade relativa de $69,6 \%$, velocidade do vento a $2 \mathrm{~m}$ de 1,1 m/s, insolação diária de 7,8 h, evapotranspiração de referência de 4,7 mm e precipitação anual de 1.342,4 mm (Bastos e Andrade Júnior, 2016). As classes de solo predominantes são Latossolos e Argissolos Vermelho-Amarelo. As características granulométricas e físico-hídricas típicas dos solos dessas classes na região são apresentadas na Tabela 1 (Melo et al., 2014). Com base nos teores de argila e areia total (areia grossa mais fina), os solos podem ser tipificados como do tipo 2, para fins de ZARC (MAPA, 2008).

Utilizou-se modelo de balanço diário de água no solo segundo proposto por Thornthwaite e Mather (1955), por meio de planilha eletrônica elaborada em ambiente Excel. Admitiu-se uma capacidade de água disponível (CAD) igual a $50 \mathrm{~mm}$, definida com base no tipo de solo (MAPA, 2008) e profundidade efetiva máxima das raízes do feijão-caupi igual a 0,4 m (Andrade Junior et al., 2001).

Tabela 1. Características granulométricas e físico-hídricas típicas dos Latossolos e Argissolos da região de Teresina, PI.

\begin{tabular}{cccccccc} 
Prof. $(\mathbf{m})$ & \multicolumn{3}{c}{ Granulometria $\left(\mathrm{g} \mathrm{kg}^{-1}\right)$} & \multicolumn{3}{c}{ Físico-hídricas } \\
& Areia Grossa & Areia Fina & Silte & Argila & CC (\%) & PMP (\%) & Ds $\left(\mathbf{g ~ c m} \mathbf{~ c m}^{-3}\right)$ \\
\hline $0,0-0,2$ & 451,8 & 190,4 & 164,5 & 193,3 & 26,2 & 12,4 & 1,58 \\
$0,2-0,4$ & 471,3 & 180,2 & 168,0 & 178,7 & 21,7 & 10,2 & 1,64 \\
\hline
\end{tabular}

CC: Capacidade de campo (-10 kPa) (\% em volume); PMP: ponto de murcha permanente (-1500 kPa) (\% em volume); Ds: densidade do solo 
Os balanços hídricos foram processados com dados de precipitação e evapotranspiração de referencia (ETo) do período de 2004 a 2018, simulando-se a semeadura do feijão-caupi nos dias 5, 15 e 25 do mês de abril de cada ano. Optou-se pelo mês de abril já que é recomendada a semeadura do feijão-caupi no final do período chuvoso, tendo em conta que a exigência hídrica do feijão-caupi é moderada, bem como para favorecer a secagem das vagens no campo (Andrade Junior et al., 2017). Posteriormente, fez-se amostragem para seleção de simulações de balanço hídrico contemplando os seguintes cenários: A: sem deficiência hídrica durante o ciclo de cultivo do feijão-caupi (cenário favorável); B) deficiência hídrica nas fases III e IV; C) deficiência hídrica na fase IV e D) Deficiência hídrica nas II, III e IV (cenário crítico). As fases de desenvolvimento do feijão-caupi foram definidas: I: da semeadura até 15 dias após a semeadura (DAS); II: de 16 a 34 DAS; III: de 35 a 53 DAS e IV: de 54 a 70 DAS.

Os valores dos coeficientes de cultura $(\mathrm{Kc})$, por fases de desenvolvimento do feijão-caupi, quando em sistema de cultivo sob palhada e preparo convencional, são apresenp tados na Tabela 2. Esses valores de Kc foram quantificados em ensaios de campo conduzidos nas mesmas condições de clima e solo por Andrade Junior et al. (2018).

A estimativa da evapotranspiração máxima (ETm) e real (ETr) do feijão-caupi, em cada sistema de cultivo, foi efetuada pelas equações apresentadas abaixo. A ETr foi calculada pela diferença de armazenamento de água no solo (equação 3).

$$
\begin{aligned}
& E T m_{i}=E \mathrm{EO}_{i} \times \mathrm{Kc}_{f} \\
& \mathrm{ETr}_{i}=\mathrm{Arm}_{i}-\mathrm{Arm}_{i+1}
\end{aligned}
$$

\section{Em que:}

$E T o_{i}$ - evapotranspiração de referência no dia $i(\mathrm{~mm})$; $K c_{f}$ - coeficiente da cultura na fase $f(f$ variando de 1 a 4$)$; $\mathrm{Arm}_{i}=$ armazenamento de água no solo no dia $i(\mathrm{~mm})$; $E T r_{i}$ - evapotranspiração real da cultura no dia $i(\mathrm{~mm})$; $\mathrm{Arm}_{i}$ - armazenamento de água no solo no dia $i(\mathrm{~mm})$; $\mathrm{Arm}_{(i+1)}$ - armazenamento de água no solo no dia $i+1$ (mm).

O índice de satisfação da necessidade de água (ISNA) do feijão-caupi, em cada fase de desenvolvimento, foi calculado pela equação 3 .

$$
I S N A_{f}=\frac{\sum_{f=1}^{n} E T r_{f}}{\sum_{f=1}^{n} E T m_{f}}
$$

\section{Em que:}

$I S N A_{f}$ - índice de satisfação da necessidade de água do feijão-caupi na fase f; $\sum_{f=1}^{n} E T_{f}$ - somatório da ETr do feijão-caupi na fase $f(\mathrm{~mm})$ ( $f$ variando de 1 a 4$)$;

$\sum_{f=1}^{n} E_{T m}$ - somatório da ETm do feijão-caupi na fase $f$ $(\mathrm{mm})(f$ variando de 1 a 4$)$;

\section{Resultados e Discussão}

Os valores precipitação e evapotranspiração de referência (ETo) registrados durante os períodos de simulação, nos diferentes cenários avaliados são apresentados na Figura 1. A ETo média diária variou de $1,9 \mathrm{~mm}$, no cenário A (sem deficiência hídrica no solo) (Figura 1A), a 3,1 mm, no cenário D (deficiência hídrica nas II, III e IV) (Figura 1D). Nos cenários B (deficiência hídrica nas fases III e IV) e C (deficiência hídrica na fase IV), a ETo média diária foi de $2,9 \mathrm{~mm}$ e $2,7 \mathrm{~mm}$, respectivamente (Figuras 1B e 1C). A faixa de variação nos valores de ETo diária (de 1,9 a 3,1 mm) é considerada normal para essa época do ano na região de Teresina, já que a nebulosidade elevada, típica do final do período chuvoso, promove redução na radiação solar global, com reflexo direto na estimativa da ETo (Bastos e Andrade Junior, 2016).

Quanto a precipitação, houve variação significativa nos valores totais registrados entre os cenários avaliados, uma vez que se objetiva avaliar o desempenho dos sistemas de cultivo sob palhada e preparo convencional quanto ao nível de atendimento das necessidades de água do feijão-caupi em diferentes condições de disponibilidade de água no solo. O total máximo obtido foi de $241,0 \mathrm{~mm}$, no cenário sem deficiência hídrica no solo (Figura 1A), e o mínimo de 61,5 mm, no cenário com deficiência hídrica nas II, III e IV (Figura 1D).

Nos cenários B (deficiência hídrica nas fases III e IV) e C (deficiência hídrica na fase IV) foram observados registros totais de precipitação de 148,7 mm e 241,6 mm, respectivamente (Figuras 1B e 1C). A precipitação total no cenário $C$ (241,6 mm) foi muito próxima da registrada no cenário A (241,1 mm); entretanto, no cenário $\mathrm{C}$ houveram registros de precipitação até os 46 dias após semeadura (DAS), enquanto no cenário $\mathrm{A}$, os registros de precipitação se estenderam durante todo o ciclo de cultivo, com concentração importante de precipitação (83,8 mm) dos 46 aos 49 DAS,

Tabela 2. Coeficiente de cultura (Kc), por fases de desenvolvimento do feijão-caupi, cultivar BRS Itaim, cultivado em preparo convencional (PC) e plantio direto (PD). Teresina, PI, 2016.

\begin{tabular}{lcccc} 
Sistema & \multicolumn{4}{c}{ Fases de desenvolvimento (DAS) } \\
de cultivo & I (S - 15) & II (16 a 34) & III (35 a 53) & IV (54 a 70) \\
\hline PC & 0,50 & 0,57 & 1,32 & 0,59 \\
PD & 0,30 & 0,44 & 1,01 & 0,60 \\
\hline
\end{tabular}


Figura 1. Precipitação e evapotranspiração de referência (ETo) registrados durante os cenários avaliados. A - Sem deficiência hídrica; B - Deficiência hídrica nas fases III e IV; C - Deficiência hídrica na fase IV e D - Deficiência hídrica nas II, III e IV.
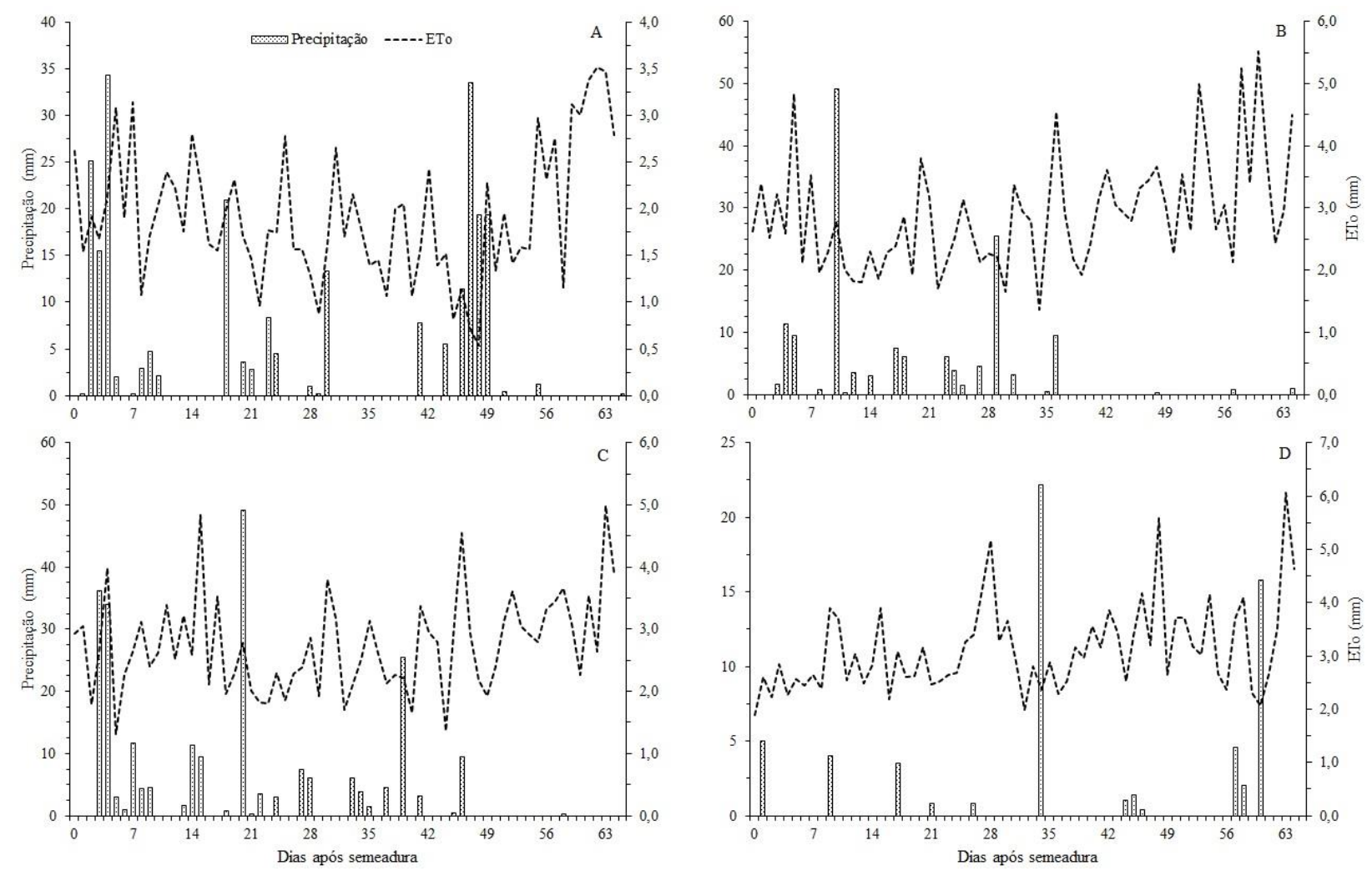

que possibilitou não haver deficiência hídrica no solo na fase IV (Figuras 1C e 1A). A precipitação média histórica (1980-1999) para o final da estação chuvosa em Teresina é de $240,0 \mathrm{~mm}$ (abril) e 103,0 mm (maio) (Bastos e Andrade Junior, 2000), portanto, muito próximos dos totais de precipitação obtidos durante o ciclo de cultivo do feijão-caupi (Figura 1), indicando que os balanços hídricos selecionados representam bem os cenários avaliados.

Os valores de armazenamento e disponibilidade de água no solo durante o ciclo do feijão-caupi sob sistema de cultivo convencional (PC) e plantio direto (PD) são apresentados na Figura 2. Em todos os cenários avaliados, o armazenamento e disponibilidade de água no solo durante o ciclo de cultivo do feijão-caupi em sistema plantio direto (PD) foi superior ao sistema de cultivo convencional (PC). No cenário A (sem deficiência hídrica), o armazenamento e disponibilidade de água no solo em sistema plantio direto foram 45,0 mm e 90,0\%, respectivamente. Esses valores são apenas $2,83 \%$ superior em comparação ao sistema de cultivo convencional ( $43,8 \mathrm{~mm}$ e $87,7 \%$ ) (Tabela 3), indicando que sob oferta adequada de água para o feijão-caupi durante o ciclo, o sistema de cultivo sob palhada não apresenta vantagem adicional em termos de disponibilidade de água no solo em relação ao sistema convencional.

Por outro lado, no cenário D (deficiência hídrica nas II, III e IV), o armazenamento e disponibilidade de água

no solo em sistema plantio direto $(33,7 \mathrm{~mm}$ e $67,5 \%)$ foi $24,4 \%$ superior em comparação ao sistema de cultivo convencional (28,0 $\mathrm{mm}$ e $56,0 \%$ ) (Tabela 3), indicando que não havendo oferta adequada de água para o feijão-caupi durante o ciclo, o sistema de cultivo sob palhada permite maior retenção e disponibilidade de água no solo para a cultura em relação ao sistema convencional. 0 aumento na disponibilidade de água no solo proporcionado pelo sistema plantio direto em comparação ao sistema convencional foi de $23,0 \%, 35,3 \%$ e $32,2 \%$, nas fases II, III e IV, respectivamente (Tabela 3). Nos cenários B (deficiência hídrica nas fases III e IV) e C (deficiência hídrica na fase IV), o acréscimo na disponibilidade de água para o feijão-caupi variou de $8,9 \%$ (C) a 13,5\% (B), com economia de água de $13,4 \%$ a $38,1 \%$ nas fases III e IV, respectivamente (Tabela 3).

$O$ aumento da disponibilidade de água no solo sob plantio direto tem sido observado por alguns autores (Stone e Silveira, 2000; Costa et al., 2003; Silva et al., 2008). Costa et al. (2003), em estudo conduzido em Latossolo Bruno alumínico câmbico (629 $\mathrm{g} \mathrm{kg}^{-1}$ de argila), em Guarapuava (PR), observaram aumento de $26 \%$ (de 0,38 para $0,48 \mathrm{~m}^{3} \mathrm{~m}^{-3}$ ) no conteúdo de água volumétrica na camada de 0-0,1 m. Segundo os autores, dois fatores principais podem ter contribuído para a maior umidade na camada superficial do solo em plantio direto: a maior infiltração de água no solo, 
Figura 2. Armazenamento e disponibilidade de água no solo, por fase de desenvolvimento do feijão-caupi, em sistema de cultivo sob palhada e convencional nos cenários avaliados. A - Sem deficiência hídrica; B - Deficiência hídrica nas fases III e IV; C - Deficiência hídrica na fase IV e D - Deficiência hídrica nas II, III e IV.
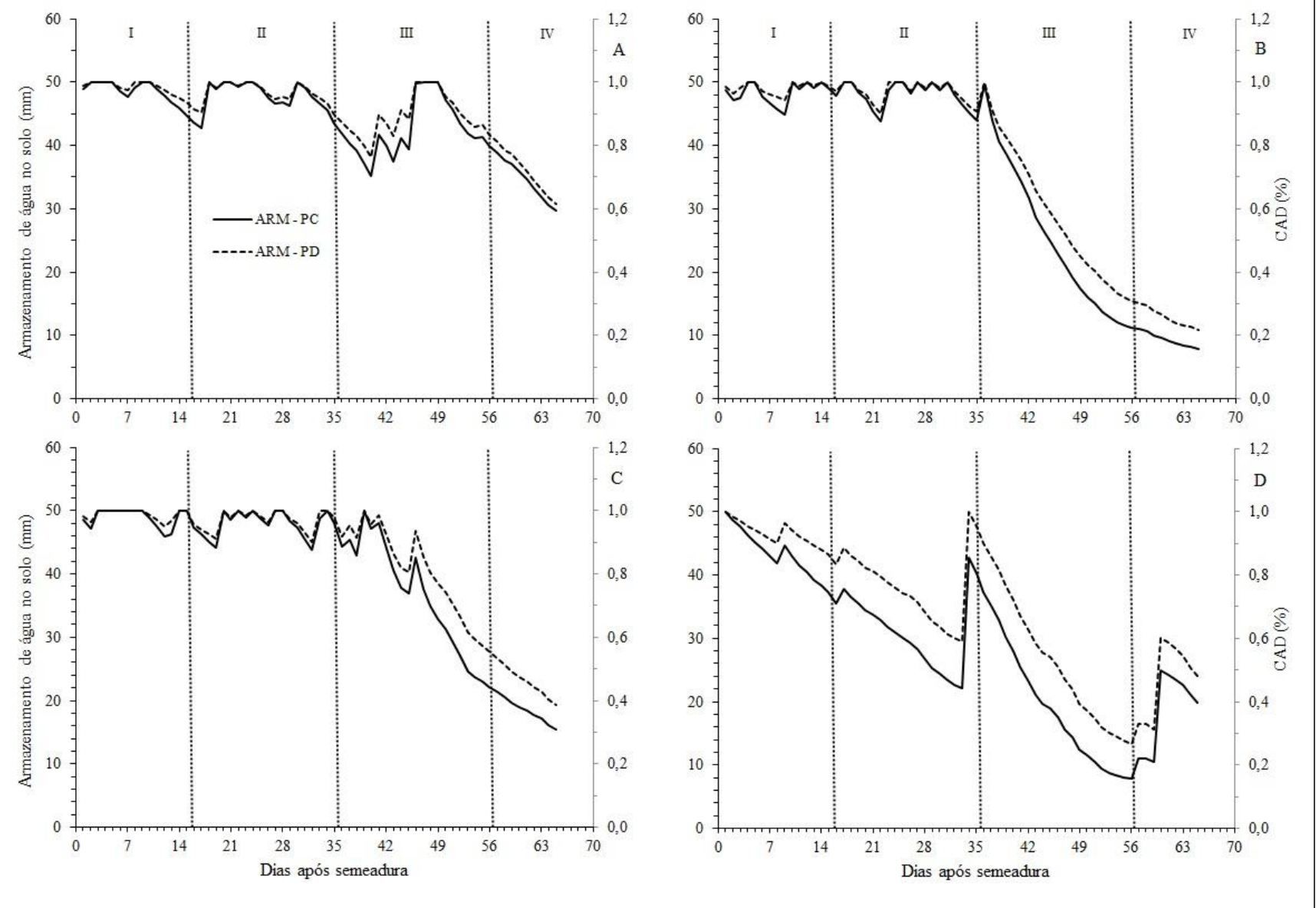

decorrente da não formação de selamento superficial, e a menor evaporação de água, devido a cobertura do solo por resíduos (Dalmago e Bergamaschi, 2017).

Tendência semelhante foi observada por Silva et al. (2008) ao avaliarem as alterações nos atributos físico-hídricos de um Latossolo Vermelho-Amarelo distrófico, textura franco-arenosa, sob sistema de cultivo plantio direto, em Campo Verde, MT. Os autores verificaram acréscimo de $29,8 \%$ na disponibilidade de água do solo quando cultivado sob plantio direto por oito anos. 0 acréscimo na disponibilidade de água no solo sob plantio direto deve-se a maior retenção de água na capacidade de campo, devido à melhor distribuição do diâmetro de poros (aumento da microporosidade), uma vez que a retenção de água no ponto de murcha depende mais da textura do solo, que não é alterada pelo manejo (Stone et al., 2012).

Os valores de evapotranspiração máxima (ETm) e real (ETr) acumuladas do feijão-caupi, sob sistema de cultivo convencional (PC) e plantio direto (PD), nos diferentes cenários avaliados são apresentados na Figura 3. Os valores de ETm durante o ciclo de cultivo do feijão-caupi, em cultivo convencional, totalizaram 90,8 mm (A), 146,9 mm (B),
$137,5 \mathrm{~mm}$ (C) e 160,1 mm (D), enquanto em cultivo plantio direto, foram iguais a 71,6 $\mathrm{mm}$ (A), 115,9 $\mathrm{mm}$ (B), 107,9 mm (C) e 125,5 mm (D) (Tabela 4). Em todos os cenários avaliados, a ETm do feijão-caupi em sistema de cultivo convencional foi $31,3 \%$ superior ao plantio direto. Em termos de fases do ciclo, esses percentuais de acréscimo foram da ordem de $66,7 \%$ (I), 29,5\% (II) e 30,7\% (III), enquanto na fase IV observou uma ligeira redução de -1,7\% (Tabela 4).

A literatura relata que o feijão-caupi possui requerimento de água na faixa entre 250 - $300 \mathrm{~mm}$, que varia com época do ano, cultivar, sistema de cultivo e manejo de irrigação (Andrade Junior et al., 2000). A redução do requerimento de água pelo feijão-caupi sob plantio direto observada no estudo pode ser atribuída aos menores valores de Kc do feijão-caupi quando em cultivo plantio direto (Tabela 2) associado à baixa demanda atmosférica da região (abril - maio), comprovado pelos reduzidos valores de ETo registrados no período (médias de 1,9 a 3,1 mm) (Figura 1) (Bastos e Andrade Junior, 2016).

Nascimento et al. (2001) verificaram que a demanda total de água para o feijoeiro comum (Phaseolus vulgaris) sob preparo convencional do solo foi de $325 \mathrm{~mm}$, enquanto 
Tabela 3. Médias de armazenamento (ARM, mm) e disponibilidade de água no solo (CAD, \%) durante as fases de desenvolvimento do feijão-caupi, em sistema de cultivo sob palhada e convencional, nos cenários avaliados.

\begin{tabular}{|c|c|c|c|c|c|c|}
\hline \multirow{2}{*}{ Cenário } & \multirow{2}{*}{ Fases } & \multicolumn{2}{|c|}{ PC } & \multicolumn{2}{|c|}{ PD } & \multirow{2}{*}{$\begin{array}{c}\Delta \\
(\%)\end{array}$} \\
\hline & & ARM $(\mathrm{mm})$ & CAD (\%) & ARM (mm) & CAD (\%) & \\
\hline \multirow{5}{*}{ A } & 1 & 48,6 & 97,1 & 49,2 & 98,3 & 1,3 \\
\hline & ॥ & 47,9 & 95,7 & 48,5 & 96,9 & 1,2 \\
\hline & III & 42,9 & 85,8 & 44,9 & 89,8 & 4,7 \\
\hline & IV & 36,0 & 72,0 & 37,5 & 74,9 & 4,1 \\
\hline & Ciclo & 43,8 & 87,7 & 45,0 & 90,0 & 2,8 \\
\hline \multirow{5}{*}{ B } & I & 48,3 & 96,7 & 49,1 & 98,1 & 1,5 \\
\hline & $\|$ & 48,3 & 96,5 & 48,7 & 97,4 & 0,9 \\
\hline & III & 28,2 & 56,5 & 32,0 & 64,0 & 13,4 \\
\hline & IV & 9,9 & 19,7 & 13,6 & 27,2 & 38,1 \\
\hline & Ciclo & 33,7 & 67,3 & 35,8 & 71,7 & 13,5 \\
\hline \multirow{5}{*}{ C } & I & 49,0 & 97,9 & 49,4 & 98,8 & 0,9 \\
\hline & $\|$ & 47,9 & 95,8 & 48,4 & 96,9 & 1,1 \\
\hline & III & 39,2 & 78,5 & 42,7 & 85,3 & 8,7 \\
\hline & IV & 19,5 & 39,1 & 24,4 & 48,8 & 24,8 \\
\hline & Ciclo & 38,9 & 77,8 & 41,2 & 82,4 & 8,9 \\
\hline \multirow{5}{*}{ D } & I & 43,4 & 86,9 & 46,6 & 93,1 & 7,2 \\
\hline & ॥ & 30,8 & 61,5 & 37,8 & 75,7 & 23,0 \\
\hline & III & 21,7 & 43,4 & 29,3 & 58,7 & 35,3 \\
\hline & IV & 16,1 & 32,1 & 21,2 & 42,5 & 32,2 \\
\hline & Ciclo & 28,0 & 56,0 & 33,7 & 67,5 & 24,4 \\
\hline
\end{tabular}

A - Sem deficiência hídrica; B - Deficiência hídrica nas fases III e IV;

C - Deficiência hídrica na fase IV e D - Deficiência hídrica nas II, III e IV.

que sob plantio direto a demanda foi de $260 \mathrm{~mm}$, representando uma redução de $20 \%$ do total de água aplicado no preparo convencional, bem próxima à economia de água obtida no presente estudo, que variou de 21,6 a 28,4\% (Tabela 4). 0 maior requerimento de água pelo feijão comum é explicado por seu maior ciclo de cultivo em relação ao feijão-caupi.

Stone e Moreira (2000) verificaram que sob plantio direto com cobertura de palhada o uso da água pelo feijoeiro foi mais eficiente em relação ao plantio direto sem cobertura de palhada. Para os autores, com a cultivar Safira, de plantas eretas, a produtividade obtida nesse último sistema, com $400 \mathrm{~mm}$ de água, foi semelhante à obtida com $240 \mathrm{~mm}$ no plantio direto com cobertura morta, representando uma economia de água de $40 \%$. Com a cultivar Aporé, por ter plantas prostradas, a economia foi menos expressiva, de $14 \%$, bem próxima a obtida no presente estudo.

Os valores de ETr no sistema de cultivo sob plantio direto foram inferiores aos obtidos sob preparo convencional, notadamente, nas fases I a III. Contudo, na fase IV, houve acréscimo nos valores de ETr entre os dois sistemas de cultivo (Tabela 4), cuja percentagem variou de 2,5\% a $23 \%$ em função do cenário avaliado (Tabela 4). Redução nos valores de evapotranspiração nas fases iniciais de desenvolvimen- to do feijoeiro cultivado sob plantio direto também foram observados por Stone e Silva (1999) e Stone et al. (2006). Essa redução deveu-se notadamente ao decréscimo na taxa de evaporação de água no solo nos estágios iniciais de desenvolvimento do feijoeiro (Stone et al., 2006). Por outro lado, Andrade et al. (2002) observaram que a ETr do feijoeiro apresentou ao final do ciclo valores menores à medida que a porcentagem de cobertura do solo pela palhada foi maior.

A economia de água foi maior nas fases iniciais de desenvolvimento (fase I), em todos os cenários avaliados, com valores da ordem de 65,1\% (A), 65\% (B), 65,8 (C) e $56,3 \%$ (D). Stone et al. (2006) avaliando o efeito na economia de água de diferentes culturas de cobertura do solo, concluíram que as maiores diferenças entre as palhadas das culturas de cobertura, com relação à evapotranspiração do feijoeiro, ocorreram nos estádios iniciais, em que as plantas do feijoeiro cobriam menos o solo, corroborando com a mesma tendência do presente estudo.

Os valores médios do índice de satisfação da necessidade de água (ISNA), por fase de desenvolvimento do feijão-caupi, em sistema de cultivo sob palhada e convencional, em todos os cenários avaliados, são apresentados na Figura 4. 
Figura 3. Evapotranspiração acumulada do feijão-caupi em sistema de cultivo sob palhada e convencional nos cenários avaliados. A - Sem deficiência hídrica; B - Deficiência hídrica nas fases III e IV; C - Deficiência hídrica na fase IV e D - Deficiência hídrica nas II, III e IV.
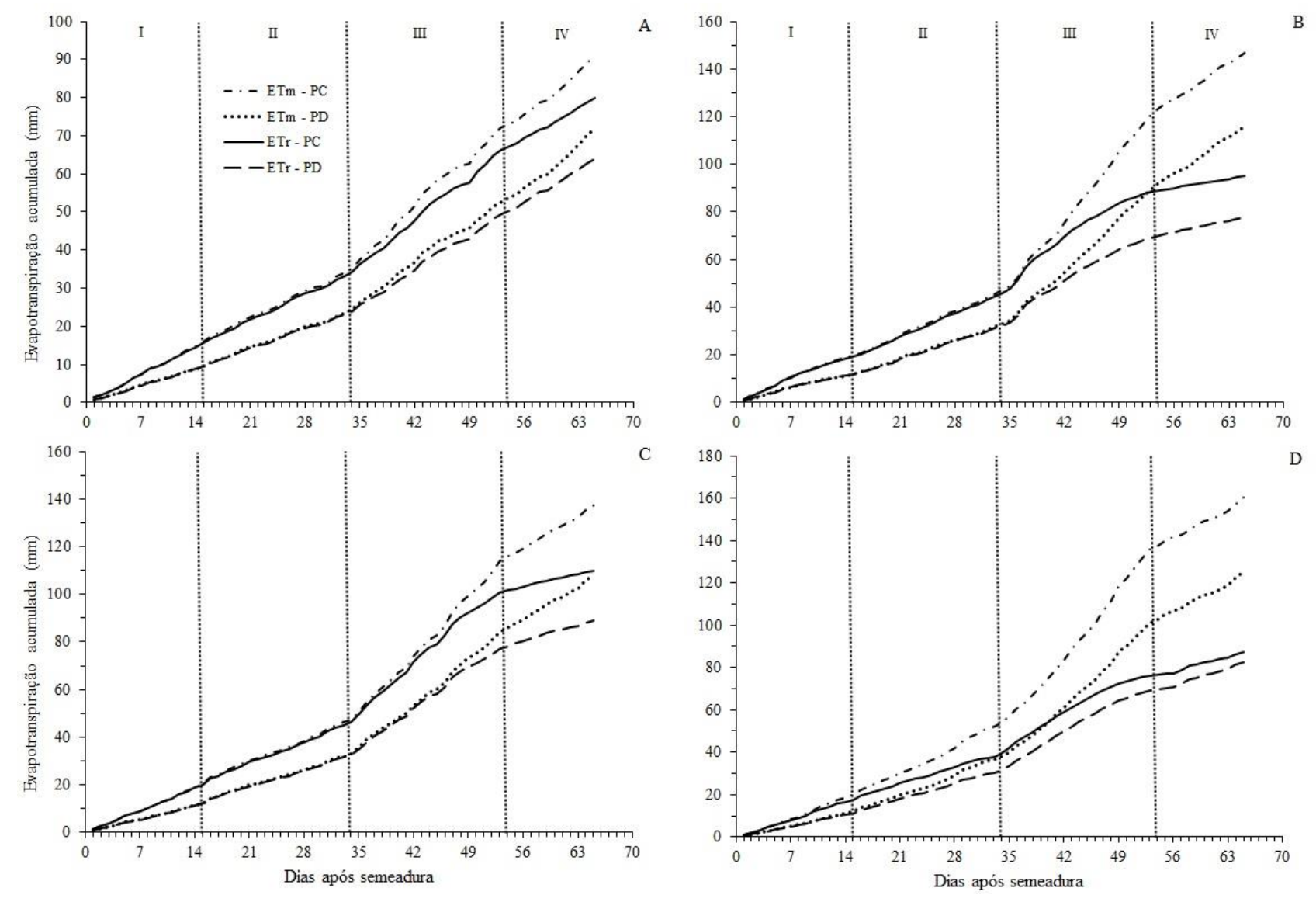

Tabela 4. Totais de evapotranspiração máxima (ETm, $\mathrm{mm}$ ) e real (ETr, $\mathrm{mm}$ ) durante as fases de desenvolvimento do feijão-caupi, em sistema de cultivo sob palhada e convencional, nos cenários avaliados.

\begin{tabular}{|c|c|c|c|c|c|c|c|}
\hline \multirow[t]{2}{*}{ Cenário } & \multirow[t]{2}{*}{ Fases } & \multicolumn{2}{|c|}{$\mathrm{ETm}(\mathrm{mm})$} & \multirow{2}{*}{$\begin{array}{c}\Delta \\
(\%)\end{array}$} & \multicolumn{2}{|c|}{$\mathrm{ETr}(\mathrm{mm})$} & \multirow{2}{*}{$\begin{array}{c}\Delta \\
(\%)\end{array}$} \\
\hline & & $P C$ & PD & & PC & PD & \\
\hline \multirow{5}{*}{ A } & I & 16,0 & 9,6 & 66,7 & 15,7 & 9,5 & 65,1 \\
\hline & ॥ & 19,2 & 14,8 & 29,5 & 18,5 & 14,4 & 28,2 \\
\hline & III & 36,9 & 28,2 & 30,7 & 32,1 & 25,6 & 25,7 \\
\hline & IV & 18,7 & 19,0 & $-1,7$ & 13,6 & 14,4 & $-5,2$ \\
\hline & Ciclo & 90,8 & 71,6 & 31,3 & 79,9 & 63,8 & 28,4 \\
\hline \multirow{5}{*}{ B } & I & 19,9 & 11,9 & 66,7 & 19,5 & 11,8 & 65,0 \\
\hline & ॥ & 27,2 & 21,0 & 29,5 & 26,4 & 20,5 & 28,7 \\
\hline & III & 73,5 & 56,3 & 30,7 & 42,5 & 36,7 & 15,8 \\
\hline & IV & 26,3 & 26,7 & $-1,7$ & 6,8 & 8,8 & $-23,0$ \\
\hline & Ciclo & 146,9 & 115,9 & 31,3 & 95,1 & 77,8 & 21,6 \\
\hline \multirow{5}{*}{ C } & I & 20,2 & 12,1 & 66,7 & 20,0 & 12,0 & 65,8 \\
\hline & $\|$ & 27,1 & 20,9 & 29,5 & 26,2 & 20,4 & 28,5 \\
\hline & III & 66,8 & 51,1 & 30,7 & 54,5 & 44,7 & 21,8 \\
\hline & IV & 23,4 & 23,8 & $-1,7$ & 9,3 & 11,8 & $-20,9$ \\
\hline & Ciclo & 137,5 & 107,9 & 31,3 & 110,0 & 89,0 & 23,8 \\
\hline \multirow{5}{*}{ D } & I & 20,2 & 12,1 & 66,7 & 17,8 & 11,4 & 56,3 \\
\hline & $\|$ & 33,4 & 25,8 & 29,5 & 21,7 & 20,0 & 8,6 \\
\hline & III & 82,2 & 62,9 & 30,7 & 36,8 & 37,8 & $-2,5$ \\
\hline & IV & 24,3 & 24,7 & $-1,7$ & 11,3 & 13,5 & $-16,4$ \\
\hline & Ciclo & 160,1 & 125,5 & 31,3 & 87,6 & 82,6 & 11,5 \\
\hline
\end{tabular}


Figura 4. Índice de satisfação da necessidade de água (ISNA), por fase de desenvolvimento do feijão-caupi, em sistema de cultivo sob palhada e convencional, nos cenários avaliados. A - Sem deficiência hídrica; B - Deficiência hídrica nas fases III e IV; C - Deficiência hídrica na fase IV e D - Deficiência hídrica nas II, III e IV.
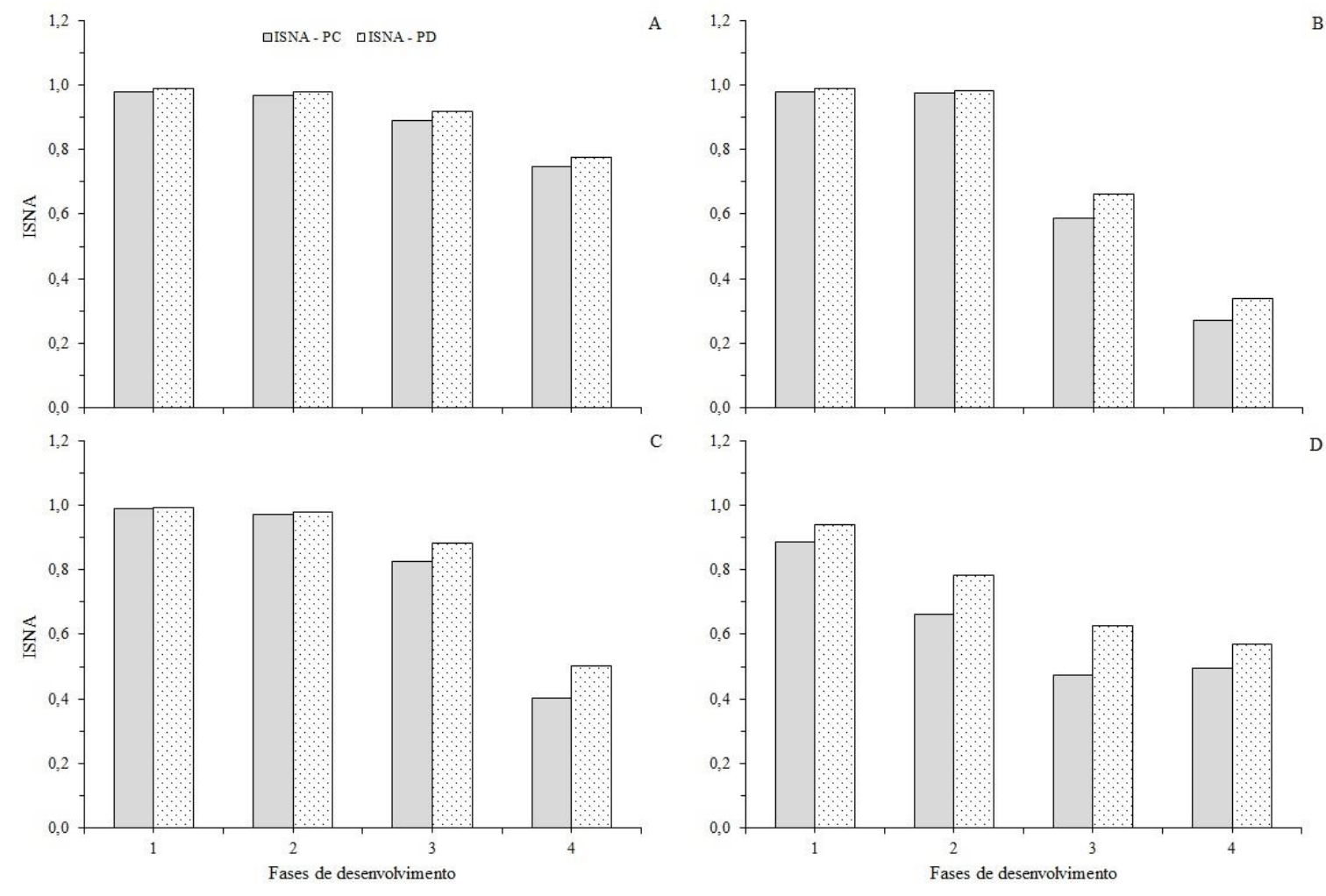

Em todos os cenários avaliados, em consequência do efeito combinado do aumento da ETm e ETr em todas as fases de desenvolvimento, houve acréscimo nos valores médios de ISNA do feijão-caupi. Contudo, a magnitude do aumento do ISNA foi dependente da disponibilidade de água no solo em cada cenário avaliado. Quando a cultura se desenvolve em condição de oferta hídrica adequada e sem deficiência hídrica no solo, não ocorre alteração sensível nos valores de ISNA entre os dois sistemas de cultivo, em todas as fases de desenvolvimento. Os valores de ISNA médios para todo o ciclo de cultivo foram iguais a 0,90 , sob sistema convencional, e 0,91, sob plantio direto, com variação de apenas 2,2\% (Tabela 5). Nessa condição, a adoção do sistema plantio direto não proporciona os benefícios quanto ao aumento da disponibilidade de água no solo para as plantas.

Por outro lado, quando a cultura se desenvolve em condição de restrição hídrica e com deficiência hídrica nas fases II, III e IV, ocorre alteração significativa nos valores de ISNA entre os dois sistemas de cultivo, notadamente na fase II de maior exigência hídrica do feijão-caupi. Na fase II, o valor de ISNA do feijão-caupi sob preparo convencional foi de 0,66 ao passo que sob plantio direto foi de 0,78 , o que representa um acréscimo de $18,6 \%$. Durante a fase III, de maior exigência hídrica do feijão-caupi, ocorreu redu- ção nos valores de ISNA nos dois sistemas de cultivo (ISNA $=0,47$, sob preparo convencional, e ISNA $=0,63$, em plantio direto), o que resultou em um acréscimo de 32,1\%. Na fase IV, os valores de ISNA foram iguais a 0,49 (PC) e 0,57 (PD), o que representa um aumento de 15,8\%. Em termos médios, durante todo o ciclo de cultivo, houve aumento de $18,2 \%$ nos valores de ISNA do feijão-caupi cultivado sob plantio direto em comparação ao preparo convencional, que provavelmente, dependendo da textura do solo, poderá impactar sobremaneira no zoneamento agrícola de risco climático, ampliando a janela de plantio considerada de baixo risco climático para a cultura.

Meireles et al. (2003), avaliando o risco climático do feijoeiro em Goiás, concluíram que a utilização do sistema plantio direto proporcionou aumento da ocorrência de áreas com menor risco e prolongamento do período favorável de semeadura, em relação ao sistema preparo convencional. Ressaltam que esses efeitos foram mais evidentes quanto maior a porcentagem da cobertura do solo pela palhada.

De fato, a redução da evaporação da água e o aumento da disponibilidade de água no solo proporcionada pela adoção do plantio direto, permite que o atendimento da necessidade de água do feijão-caupi possa ser flexibilizado quando cultivado em sistema plantio direto, já que ocorre 
Tabela 5. Médias do índice de satisfação da necessidade de água (ISNA) durante as fases de desenvolvimento do feijão-caupi, em sistema de cultivo sob palhada e convencional, nos cenários avaliados.

\begin{tabular}{|c|c|c|c|c|c|c|c|c|c|}
\hline \multirow[t]{2}{*}{ Cenário } & \multirow[t]{2}{*}{ Fases } & \multicolumn{2}{|c|}{ ISNA } & \multirow{2}{*}{$\begin{array}{c}\Delta \\
(\%)\end{array}$} & \multirow[t]{2}{*}{ Cenário } & \multirow[t]{2}{*}{ Fases } & \multicolumn{2}{|c|}{ ISNA } & \multirow{2}{*}{$\begin{array}{c}\Delta \\
(\%)\end{array}$} \\
\hline & & PC & PD & & & & PC & PD & \\
\hline \multirow{5}{*}{ A } & I & 0,98 & 0,99 & 0,9 & \multirow{4}{*}{$C$} & I & 0,99 & 0,99 & 0,5 \\
\hline & $\|$ & 0,97 & 0,98 & 1,0 & & $\|$ & 0,97 & 0,98 & 0,7 \\
\hline & III & 0,89 & 0,92 & 3,3 & & III & 0,82 & 0,88 & 6,8 \\
\hline & IV & 0,75 & 0,78 & 3,6 & & IV & 0,40 & 0,50 & 24,3 \\
\hline & Ciclo & 0,90 & 0,91 & 2,2 & & Ciclo & 0,80 & 0,84 & 8,1 \\
\hline \multirow{5}{*}{ B } & 1 & 0,98 & 0,99 & 1,0 & \multirow{4}{*}{ D } & I & 0,89 & 0,94 & 6,1 \\
\hline & $\|$ & 0,98 & 0,98 & 0,6 & & $\|$ & 0,66 & 0,78 & 18,6 \\
\hline & III & 0,59 & 0,66 & 12,4 & & III & 0,47 & 0,63 & 32,1 \\
\hline & IV & 0,27 & 0,34 & 25,7 & & IV & 0,49 & 0,57 & 15,8 \\
\hline & Ciclo & 0,70 & 0,74 & 9,9 & & Ciclo & 0,63 & 0,73 & 18,2 \\
\hline
\end{tabular}

A - Sem deficiência hídrica; B - Deficiência hídrica nas fases III e IV;

C - Deficiência hídrica na fase IV e D - Deficiência hídrica nas II, III e IV

redução do risco climático por deficiência hídrica no solo. Assim, admitindo-se o cenário mais crítico em termos de disponibilidade de água no solo e garantindo-se uma margem de segurança, propõe-se que essa redução seja da ordem de $7 \%$, na fase I, e de $20 \%$, na fase III, nos valores atuais de ISNA praticados para fins de ZARC do feijão-caupi (ISNA $=0,6$, na fase I, e ISNA = 0,55, na fase III) (MAPA, 2018). Dessa forma, os valores de ISNA para o ZARC do feijão-caupi em plantio direto passariam a ser iguais a 0,55, na fase I, e 0,45, na fase III.

É importante ressaltar que, apesar dos valores de Kc do feijão-caupi, em sistema plantio direto e convencional, utilizados no presente estudo, terem sido obtidos em ensaios conduzidos em condições de campo (Andrade Junior et al., 2018), que proporcionou estimativas confiáveis da ETm da cultura, os valores de ETr e ISNA foram obtidos com base em simulações de balanço de água no solo, o que não dispensa a realização de estudos em condições de campo. Portanto, é fundamental que sejam executados estudos em campo para quantificação dos valores de ETr e ISNA do feijão-caupi, de forma a comprovar os percentuais de redução nos valores de ISNA proposta neste estudo.

\section{Conclusões}

Em cenário sem deficiência hídrica no solo, não há variação sensível do ISNA do feijão-caupi cultivado sob plantio direto comparado ao cultivado sob preparo convencional. O ISNA do feijão-caupi cultivado sob sistema plantio direto é superior ao cultivado em solo sob preparo convencional em condições de deficiência hídrica no solo. Assim, propõe-se redução de 7\% (fase I) e de 20\% (fase III) nos atuais valores de ISNA para o feijão-caupi praticados pelo MAPA, quando o feijão-caupi for cultivado sob plantio direto.

\section{Referências Bibliográficas}

ALLEN, R.G.; PEREIRA, L.S.; RAES, D.; SMITH, M. Crop evapotranspiration: guidelines for computing crop water requirements. Roma: FAO, 1998. 328p. (FAO Irrigation and Drainage Papers, 56).

AMARAL, J.A.B.; BELTRÃO, N.E.M.; SILVA, M.T. Zoneamento agrícola do feijão-caupi no Nordeste Brasileiro: Safra 2005/ 2006, Estado da Paraíba. Campina Grande: Embrapa Algodão, 2005. p.1-9. Comunicado Técnico, 253.

BASTOS, E.A.; ANDRADE JÚNIOR, A.S. Dados agrometeorológicos para o município de Teresina, PI (1980- 1999). Teresina: Embrapa MeioNorte, 2000, 25p (Embrapa Meio-Norte. Documentos, 47).

ANDRADE JÚNIOR, A.S.; MELO, F. de B.; BASTOS, E.A. Zoneamento de risco climático para o feijão-caupi no Piauí. In: Reunião Nacional de Pesquisa de Caupi, 5., 2001, Teresina, Anais. Teresina: Embrapa MeioNorte, 2001. p.3-7.

ANDRADE JÚNIOR, A.S.; RODRIGUES, B.H.N.; BASTOS, E.A. Irrigação. In: CARDOSO, M. J. (Org.). A cultura do feijão-caupi no Meio-Norte do Brasil. Teresina: Embrapa Meio-Norte, 2000. p. 127 - 154. (Embrapa Meio-Norte. Circular técnica, 28).

ANDRADE JUNIOR, A.S.; BARROS, A.H.C.; SILVA, C.O.; FREIERE FILHO, F.R. Zoneamento de risco climático para a cultura do feijão-caupi no Estado do Ceará. Revista Ciência Agronômica, v.38, n.1, p.109-117, 2007.

ANDRADE JUNIOR, A.S.; BASTOS, E.A.; CARDOSO, M.J. Clima. In: BASTOS, E. A. (Ed.). Cultivo de Feijão-Caupi. 2. ed. Brasília, DF: Embrapa, 2017. Versão eletrônica.

ANDRADE JUNIOR, A.S.; BASTOS, E.A.; MONTEIRO, M.M.S; SILVA JUNIOR, J.S. Evapotranspiração e coeficiente de cultura do feijão-caupi sob sistema de cultivo convencional e plantio direto. Agrometeoros, v.26, n.1, p. 2018.

ANDRADE, R.S.; MOREIRA, J.A.A.; STONE, L.F.; CARVALHO, J.A. Consumo relativo de água do feijoeiro no plantio direto em função da porcentagem de cobertura morta do solo. Revista Brasileira de Engenharia Agrícola e Ambiental, Campina Grande, v. 6, n. 1, p. 35-38, 2002.

ASSAD, E.D., SANO, E.E., BEZERRA, H.S. Uso de modelos numéricos de terreno na espacialização de épocas de plantio. In: ASSAD, E.D., SANO, E.E. Sistemas de Informações Geográficas. Aplicações na Agricultura. Brasília: Embrapa-SPI/Embrapa Cerrados, 1998. p.311-327.

BASTOS, E.A.; ANDRADE JUNIOR, A.S. Boletim Agrometeorológico de 2015 para o município de Teresina, Piauí. Teresina: Embrapa MeioNorte, 2016. 38p. (Documentos / Embrapa Meio-Norte, ISSN 0104 - 866X; 239). 
CARDOSO, M.J.; BASTOS, E.A.; ATHAYDE SOBRINHO, C.; MELO, F.B. Rendimento de grãos do feijão-caupi BRS Itaim em função da densidade de plantio em sistemas de semeadura convencional e direta com palhada do primeiro ano. Teresina: Embrapa Meio-Norte, 2017. 7p. (Comunicado Técnico / Embrapa Meio-Norte, ISSN 0104-7647; 240).

COSTA, F.S.; ALBUQUERQUE, J.A.; BAYER, C.; FONTOURA, S.M.V.; WOBETO, C. Propriedades físicas de um Latossolo Bruno afetadas pelos sistemas plantio direto e preparo convencional. Revista Brasileira de Ciência do Solo, v. 27, n. 3, p. 527-535, 2003.

CUNHA, R.G.; ASSAD, E.D. Uma visão geral sobre zoneamento agrícola Brasil. Revista Brasileira de Agrometeorologia, v.9, n.3, n. especial, p.377-385, 2001.

DALMAGO, G.A.; BERGAMASCHI, H. Evaporation of the soil water in response to the amount of straw and evaporative demand. Agrometeoros, v.25, n.2, p.361-371, 2017.

FREIRE FILHO, F.R. (Ed.). Feijão-caupi no Brasil: produção, melhoramento genético, avanços e desafios. Teresina: Embrapa MeioNorte, 2011. $84 \mathrm{p}$.

FREIRE FILHO, F. R.; ROCHA, M.M.; RIBEIRO, V.Q.; SILVA, K.J.D.; CARVALHO, H.W.L.; CRAVO, M.S.; LOPES, A.M.; VILARINHO, A.A.; SABOYA, R.C.C.; CAVALCANTE, E.S.; COSTA, A.F.; ALCANTARA, J.P.; SITTOLIN, I.M. BRS Itaim: cultivar de feijão-caupi com grãos tipo fradinho. Teresina: Embrapa Meio-Norte, 2009. 2p.

LOCATELLI, V.E.R.; MEDEIROS, R.D.; SMIDERLE, O.J.; ALBUQUERQUE J.A.A.; ARAÚJO, W.F.; SOUZA, K.T.S. Componentes de Produção, produtividade e eficiência da irrigação do feijão-caupi no cerrado de Roraima. Revista Brasileira de Engenharia Agrícola e Ambiental, v. 18, n. 6, p. 574-580, 2014.

MAPA - Tipos de solos para fins de Zoneamento Agrícola de Risco Climático. Brasília: Secretaria de Política Agrícola, 2008, 2p. (Instrução Normativa nº 2, de 9 de Outubro de 2008).

MAPA - Zoneamento Agrícola de Risco Climático para o FeijãoCaupi, Safra 2018/2019. Brasília: Secretaria de Política Agrícola, 2018, 7p. (Portaria nº 181, de 13 de Agosto de 2018).

MEIRELES, E.J.L.; STONE, L.F.; XAVIER, L.S.; MOREIA, J.A.A. Risco climático do feijão da seca no Estado de Goiás, sob preparo de solo convencional e plantio direto. Revista Brasileira de Engenharia Agrícola e Ambiental, v.7, n.1, p.116-120, 2003.

MELO, F.B.; CARDOSO, M.J. Solos e adubação. In: BASTOS, E. A. Cultivo de feijão-caupi. 2. ed. Brasília, DF: Embrapa Meio-Norte, 2017.

MELO, F.B.; ANDRADE JUNIOR, A.S.; PESSOA, B.L.O. Levantamento, zoneamento e mapeamento pedológico detalhado da área experimental da Embrapa Meio-Norte em Teresina, PI. Teresina: Embrapa Meio-Norte, 2014. 47 p. (Embrapa Meio-Norte. Documentos, 231).
NASCIMENTO, J. L.; STONE, L.F.; OLIVEIRA, L.F.C. Demanda total de água do feijoeiro nos sistemas de plantio convencional e direto. Pesquisa Agropecuária Tropical, Goiânia, v. 31, n. 2, p. 159-161, 2001.

OLIVEIRA, S.R.M. Definição de parâmetros para estimativa de risco climático no consórcio algodão herbáceo-feijão-caupi. 2010. 109 f. Dissertação (Mestrado em Agronomia) - Universidade Federal do Piauí, Teresina.

SILVA, C.R.; ANDRADE JÚNIOR, A.S.; ALVES JÚNIOR, J.; SOUSA, A.B.; MELO, F.B.; COELHO FILHO, M.A. Calibration of Diviner $2000^{\circledR}$ capacitance probe in a Rhodic Paleudult. Scientia Agricola, Piracicaba, v. 64, p. 636640,2007

SILVA, G.J.; VALADÃO JÚNIOR, D.D.; BIANCHINI, A.; AZEVEDO, E.C.; MAIA, J.C.S. Variação de atributos físico-hídricos em Latossolo VermelhoAmarelo do cerrado mato-grossense sob diferentes formas de uso. Revista Brasileira de Ciência do Solo, v. 32, n. 5, p. 2135-2143, 2008.

SIMIDU, H.M.; SÁ, M.E.; SOUZA, L.C.D.; ABRANTERS, F.L.; SILVA M.P.; ARF, O. Efeito do adubo verde e época de semeadura sobre a produtividade do feijão, em plantio direto em região de cerrado. Acta Scientiarum Agronomy, v. 32, n. 2, p. 309-315, 2010.

STONE, L.F.; SILVEIRA, P.M.; MOREIRA, J.A.A. Efeitos do sistema plantio direto no uso da água pelas culturas e no manejo da irrigação. Goiânia: Embrapa Arroz e Feijão, 2012, 8p. (Embrapa Arroz e Feijão. Comunicado Técnico, 207).

STONE, L.F.; MOREIRA, J.A.A. Efeitos de sistemas de preparo do solo no uso da água e na produtividade do feijoeiro. Pesquisa Agropecuária Brasileira, Brasília, DF, v. 35, n. 4, p. 835-841, 2000.

STONE, L.F.; SILVA, S.C. Uso do tanque Classe A no controle da irrigação do feijoeiro no sistema plantio direto. Santo Antônio de Goiás: Embrapa Arroz e Feijão, 1999. 2 p. (Embrapa Arroz e Feijão. Pesquisa em foco, 25).

STONE, L.F.; SILVEIRA, P.M.; MOREIRA, J.A.A.; BRAZ, A.J.B.P. Evapotranspiração do feijoeiro irrigado em plantio direto sobre diferentes palhadas de culturas de cobertura. Pesquisa Agropecuária Brasileira, Brasília, DF, v. 41, n. 4, p. 577-582, 2006.

THORNTHWAITE, C.W.; MATHER, J.R. The water balance. Centerton, NJ: Drexel Institute of Technology - Laboratory of Climatology, 1955. 104p. (Publications in Climatology, vol. VIII, n.1) $\begin{array}{ll}\text { REFERENCIAÇÃO } & \text { ANDRADE JUNIOR, A. S.; BASTOS, E. A.; SILVA, M. V. P.; SILVA JUNIOR, J. S.; MONTEIRO, J. E, B. A. } \\ \text { Índice de satisfação da necessidade de água do feijão-caupi sob sistema de cultivo convencional e }\end{array}$ plantio direto. Agrometeoros, Passo Fundo, v.26, n.1, p.201-211, 2018. 


\title{
Cowpea water requirement index under conventional tillage and no-tillage cropping system
}

\author{
Aderson Soares de Andrade Junior ${ }^{1\left(^{*}\right)}$, Edson Alves Bastos ${ }^{1}$, Marcos Vinicius Pereira da Silva ${ }^{2}$, Josimar Soares da Silva Junior ${ }^{2}$ and \\ José Eduardo Boffino de Almeida Monteiro ${ }^{3}$ \\ ${ }^{1}$ Embrapa Meio-Norte. Av. Duque de Caxias, no 5.650, Bairro Buenos Aires, Caixa Postal 001 CEP 64008-780, Teresina, PI, Brazil. \\ E-mails: aderson.andrade@embrapa.br and edson.bastos@embrapa.br \\ ${ }^{2}$ UFPI-Programa de Pós-graduação em Agricultura Tropical. Campus Universitário Ministro Petrônio Portela, Bairro Ininga, CEP 64049-550 Teresina, PI. \\ Teresina, PI, Brazil. E-mails: marquim06vinicios@gmail.com and josimarssjunior@gmail.com \\ ${ }^{3}$ Embrapa Informática Agropecuária, Rua André Tosello, 209, Barão Geraldo, Caixa Postal 6041, CEP 13083-886 Campinas, SP, Brazil. \\ E-mail: eduardo.monteiro@embrapa.br \\ ${ }^{(*)}$ Corresponding author.
}

\section{ARTICLE INFO}

Article history:

Received 23 June 2018

Accepted 2 December 2018

\section{Index terms:}

water balance

water extraction

water supply index

climatic risk

\section{ABSTRACT}

The objective of this study was to quantify and compare the water need satisfaction index (ISNA) of cowpea when cultivated under no-tillage system in relation to cultivated under conventional soil tillage, in order to subsidize the climatic risk zoning of the crop. Soil water balance was used to estimate real evapotranspiration (ETr) and ISNA of cowpea in different conditions of soil water availability. Crop coefficients $(\mathrm{Kc})$ were quantified in field experiments conducted in both crops systems. Under no water deficit scenario, there was no variation in ISNA values in the different development phases of cowpea. However, under water deficit scenario the ISNA under no-tillage was 18.6\% (phase II), 32.1\% (phase III) e 15.8\% (phase IV) higher than ISNA determined under conventional soil preparation. This is due to reduction in evaporation on the soil surface cover with straw and hence increased availability of water in the soil during the growing cycle. This condition favors the expansion of the planting window considered of low climatic risk for the crop.
CITATION

ANDRADE JUNIOR, A. S.; BASTOS, E. A.; SILVA, M. V. P.; SILVA JUNIOR, J. S.; MONTEIRO, J. E, B. A. Índice de satisfação da necessidade de água do feijão-caupi sob sistema de cultivo convencional e plantio direto. Agrometeoros, Passo Fundo, v.26, n.1, p.201-211, 2018. 